\title{
Flexible Supercapacitors: A Materials Perspective
}

\author{
Soubantika Palchoudhury ${ }^{1}$, Karthik Ramasamy ${ }^{2 *}$, Ram K. Gupta ${ }^{3}$ and Arunava Gupta ${ }^{4}$ \\ ${ }^{1}$ Civil and Chemical Engineering, University of Tennessee at Chattanooga, Chattanooga, TN, United States, ${ }^{2}$ UbiQD Inc, Los \\ Alamos, NM, United States, ${ }^{3}$ Department of Chemistry, Pittsburg State University, Pittsburg, KS, United States, ${ }^{4}$ Center for \\ Materials for Information Technology, The University of Alabama, Tuscaloosa, AL, United States
}

Flexible supercapacitors are highly attractive for the large number of emerging portable lightweight consumer devices. The novelty of a flexible supercapacitor is the incorporation of flexible electrode or substrate material to combine structural flexibility with the inherently high power density of supercapacitors. Flexible supercapacitors can use non-Faradaic energy storage process as seen in the electric double layer capacitor type or a Faradaic mechanism as seen in the pseudocapacitors (PCs). In this review, we account the current progress in pseudocapacitive electrode materials, fabrication techniques and new materials for electric double layer capacitor, and different flexible substrates. Future directions in developing new materials toward improved energy density and cost-effectiveness of the flexible supercapacitors and their usage in combination with lithium-ion batteries are highlighted.

\section{OPEN ACCESS}

Edited by:

Dong Wook Chang,

Pukyong National University,

South Korea

Reviewed by:

Yan Huang,

Shenzhen Graduate School of Harbin Institute of Technology, China

Liang Zhou,

Wuhan University of Technology,

China

*Correspondence: Karthik Ramasamy karthik@ubiqd.com

Specialty section: This article was submitted to

Energy Materials,

a section of the journal

Frontiers in Materials

Received: 26 October 2018

Accepted: 31 December 2018

Published: 22 January 2019

Citation:

Palchoudhury S, Ramasamy K, Gupta RK and Gupta A (2019) Flexible

Supercapacitors: A Materials Perspective. Front. Mater. 5:83. doi: 10.3389/fmats.2018.00083
Keywords: flexible supercapacitor, electrode materials, oxides, chalcogenides, molybdates, flexible substrates

\section{INTRODUCTION}

Flexible energy storage devices are fundamental to the development of next-generation wearable, compact, and portable electronics for medical, military, and civilian applications e.g., flexible displays on phones, health tracking devices, computers, and televisions (Ko et al., 2017). To this end, flexible supercapacitors are highly attractive in comparison to batteries (LIBs) as they combine the inherent high power density ( $>10 \mathrm{~kW} / \mathrm{kg}$ ), fast charging/discharging capability, longer operation lifetime, and mechanical flexibility. Conventional supercapacitors consist of an outer case, current collectors in the form of metal foils, and positive and negative electrodes in electrolyte separated by ion transport layer. In flexible supercapacitors, the highly conducting and flexible carbon network serve as both the electrode and current collector (Shi et al., 2013b). A schematic and an example of a flexible supercapacitor is shown in Figure 1. Therefore, the structural architecture of flexible supercapacitors is made lightweight and further simplified for portable electronics. Another key difference from conventional supercapacitors is that each component in flexible supercapacitors (e.g., electrodes and packing shell) is flexible. These flexible supercapacitors can typically be of two types, electric double-layer capacitors (EDLCs), and pseudocapacitors (PCs) (Chee et al., 2016; Liu et al., 2017). EDLCs use the non-Faradaic electrostatic process to store energy. They function based on the charges accumulated at the interface between the electrolyte and the electrode, which is primarily carbon-based materials with the high specific area. In PCs, the electrode formed from conductive polymers or metal oxides use a Faradaic mechanism to store charges.

A combination of indices e.g., energy and power density, cycling stability, and areal capacitance (capacitance per unit area, $\mathrm{Fcm}^{-2}$ ) determine the performance of a flexible supercapacitor. The following section highlights the equations used to assess performance metric of EDLC and PC flexible supercapacitors. 

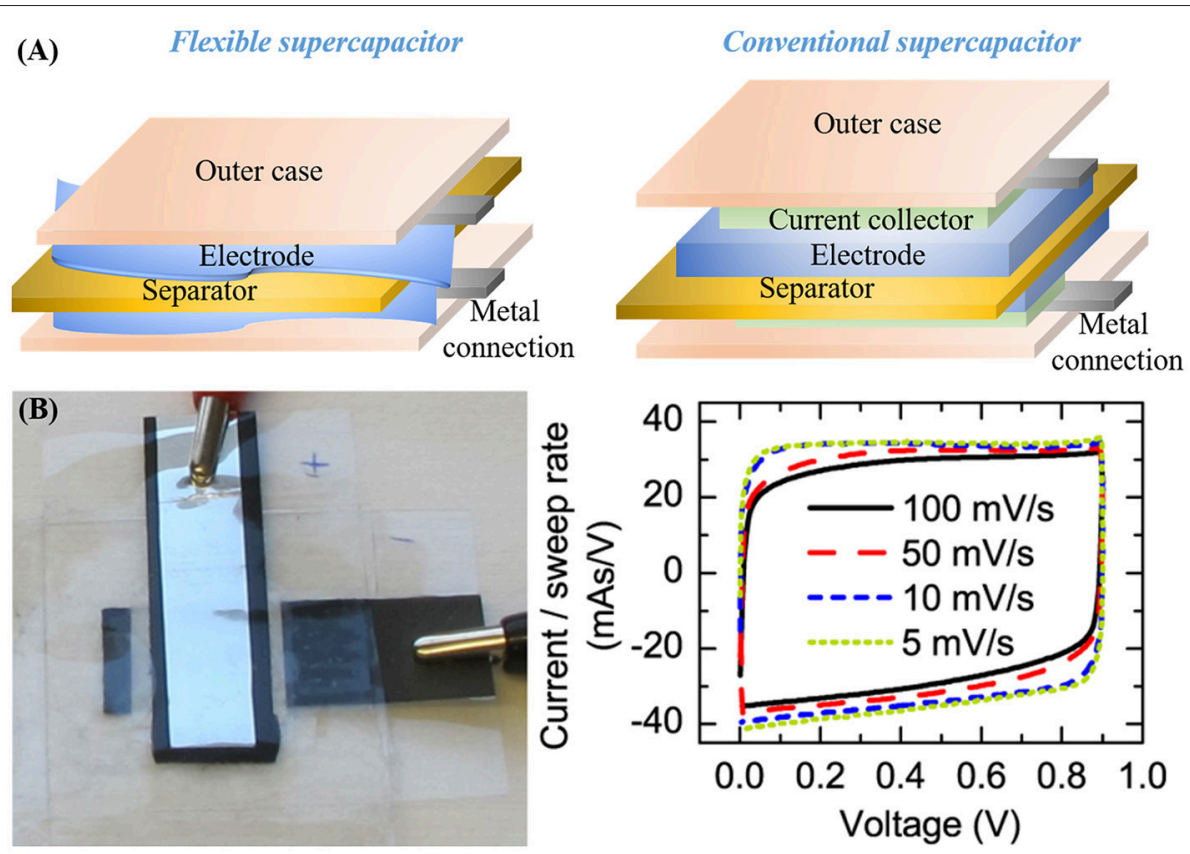

FIGURE 1 | (A) Schematic overview of a flexible supercapacitor as compared to conventional supercapacitor and (B) Photo of flexible supercapacitor composed of poly(3,4-ethylenedioxythiophene) and graphene oxide composite films on flexible graphite-poly(ethylene terephthalate) substrate and its current-voltage plot; (Lehtimaki et al., 2015) Copyright: ACS Applied Materials and Interfaces.

\section{Electric Double-Layer Capacitors}

In EDLCs, the charge accumulated at the electrode/electrolyte interfaces or capacitance $\mathrm{C}$ can be found using Equation 1 (Endo et al., 2001).

$$
C=\frac{\varepsilon}{4 \pi \delta} \int d S
$$

where, $\varepsilon$ is the dielectric constant of the electrolyte, $S$ is the electrode interface surface area, and $\delta$ is the distance from the center of the ion to the electrolyte interface. In recent literature, the specific capacitance has been calculated from the area under the cyclic voltammetry (CV) curve using Equation 2 (Lim et al., 2014).

$$
C=k \frac{\int i}{m S}
$$

where, $\mathrm{i}$ is the integrated area of the CV curve, $\mathrm{m}$ is the mass of the electrode material, $\mathrm{S}$ is the scan rate of the $\mathrm{CV}$ conducted, and $\mathrm{k}$ is a constant multiplier. The specific capacitance can also be obtained from galvanostatic discharge profile following Equation 3 (Wang et al., 2014; Zhou et al., 2014).

$$
C=k \frac{i t}{\Delta V \cdot m}
$$

where, $\mathrm{i}$ is the current, $\mathrm{t}$ is the time elapsed during the discharge process, $\mathrm{m}$ is mass of the electrode material, and $\mathrm{V}$ is the working potential range.
Finally, the energy density (E) and power density (P) for EDLCs are calculated from the CV profile, following Equations 4 and 5, respectively (Winter and Brodd, 2004; Fan et al., 2011).

$$
\begin{aligned}
E_{\text {cell }}(W h / k g) & =1 / 2 C V^{2} \\
P_{\text {cell }}(W / k g) & =\frac{E_{\text {cell }}}{\Delta t}
\end{aligned}
$$

where, $\Delta t$ is the discharge time.

\section{Pseudocapacitors}

Recently, the following method has been used to determine the performance parameters for a PC flexible supercapacitor. The stored electrode charge, $\mathrm{q}$ for PCs is calculated from the mass of $\mathrm{PC}$ material $(\mathrm{m})$, the specific capacitance $(\mathrm{C})$, and the range of $\mathrm{CV}$ operation $(\Delta \mathrm{E})$ following Faraday's law (Equation 6) (Khomenko et al., 2006).

$$
q=C \times \Delta E \times m
$$

The electrochemical capacitances for $\mathrm{CV}$ and galvanostatic charge/discharge measurements in this type of supercapacitor are determined using Equations 7 and 8, respectively (Zhang and Pan, 2015).

$$
\begin{array}{r}
C=\frac{\int i(V) d V}{2 v \Delta V S} \\
C=\frac{I \Delta t}{\Delta V}
\end{array}
$$


where, i, v, I, and S are attributed to current, scan rate $\left(\mathrm{mVs}^{-1}\right)$, applied current density, and active electrode area, respectively. The two major performance indices $\mathrm{P}$ and $\mathrm{E}$ are calculated from the galvanostatic discharge profile following Equations 9 and 4, respectively for PCs (Khomenko et al., 2006).

$$
P=\frac{V^{2}}{4 R S}
$$

where, $\mathrm{R}$ is the total resistance found using the voltage drop between two points in the discharge profile $(\Delta \mathrm{iR})$ and the applied current (i) as follows (Equation 10) (Khomenko et al., 2006; Zhang and Pan, 2015):

$$
R=\frac{\Delta i R}{2 i}
$$

Therefore, power and energy densities are two defining parameters for the performance of a flexible supercapacitor, in combination with its structural flexibility. Supercapacitors are prized for their high power density. Though the energy density $\left(\sim 5 \mathrm{Whkg}^{-1}\right)$ of supercapacitors is lower as compared to LIBs $\left(\sim 150 \mathrm{Whkg}^{-1}\right)$, there has been enormous advancements in nanostructured materials for supercapacitor electrodes and functional electrolytes to improve the energy density. The flexible and conducting electrode that also serves as the current collector is a key component for flexible supercapacitors. Therefore, materials for the electrodes are being constantly improved ( $\mathrm{Li}$ et al., 2016). Novel device fabrication techniques are also being pursued to achieve higher architectural flexibility at lower cost. Recently, Dong et al. reported three broad classifications of flexible supercapacitors into fiber-like, paper-like, and threedimensional porous materials based on their microstructure and morphology in an attempt to summarize the huge advances in the field (Dong et al., 2016a). The structural design and its associated fabrication techniques also greatly influence the flexibility of supercapacitors as summarized in the review by Zhang et al. (2015). This brief review captures the recent advances made in electrode materials for flexible supercapacitors.

\section{RECENT PROGRESS IN FLEXIBLE SUPERCAPACITOR MATERIALS}

Recently, a wide range of new pseudocapacitive electrode materials has been investigated with the aim of increasing the energy density of flexible supercapacitors. PCs essentially have a higher charge storage capacity compared to the EDLCs but are limited by high cost and poor cyclic stability. Nanostructured redox active materials are attractive for PCs as they can increase the active sites for Faradaic redox reaction at the electrode/electrolyte interface for enhanced charge storage. To this end, a large group of transition metal oxides are known for their promising pseudocapacitive behavior. Conventionally, several binary metal oxides (e.g., iron oxide, $\mathrm{RuO}_{2}, \mathrm{NiO}, \mathrm{Co}_{3} \mathrm{O}_{4}$, $\mathrm{Mo}_{2} \mathrm{O}_{3}, \mathrm{~V}_{2} \mathrm{O}_{5}$, and $\mathrm{MnO}_{2}$ ) have exhibited large energy and power density. Among them, $\mathrm{RuO}_{2}$ in its hydrous form has been known to surpass the capacitance of carbon-based and conducting polymeric materials ( $\mathrm{Hu}$ and Chen, 2004; Oh and Nazar, 2010). $\mathrm{MnO}_{2}$ has also proved to be promising for its environmental benignity, cost-effectiveness, and good specific capacitance (Lee and Goodenough, 1999; Hu and Chen, 2004; Miller and Simon, 2008). However, ternary and higher order metal oxides are specifically attractive because they provide additional sites for pseudocapacitive redox processes to facilitate higher capacitance. For example, the ternary oxide $\mathrm{NiCo}_{2} \mathrm{O}_{4}$ is highly suitable for supporting multiple electrochemical processes as it contains mixed valence metals (Zhang and Lou, 2013; Zhang D. et al., 2014). $\mathrm{NiCo}_{2} \mathrm{O}_{4}$ nanocrystals grown on different substrates such as carbon fiber paper, nickel foam, and titanium sheets have shown good cyclic stability and high capacitance (Zhang et al., 2012; Huang et al., 2013; Mitchell et al., 2015). Recently, a highly flexible quasi solid-state supercapacitor device was fabricated by sandwiching electrodes of flower-shaped $\mathrm{NiCo}_{2} \mathrm{O}_{4}$ nanocrystals on graphene oxide (GO) substrate (Gupta et al., 2015). The device showed excellent cyclic stability, suggesting that this $\mathrm{NiCo}_{2} \mathrm{O}_{4}$-GO electrode material is highly suitable for fabrication of variable temperature and high performance flexible supercapacitor devices.

Transition metal chalcogenides $\left(\mathrm{VS}_{2}, \mathrm{CuS}, \mathrm{CoE}_{2}, \mathrm{NiE}_{2}, \mathrm{E}=\right.$ $\mathrm{S}, \mathrm{Se})$, rare-earth metal sulfides $\left(\mathrm{La}_{2} \mathrm{~S}_{3}\right.$ and $\left.\mathrm{Sm}_{2} \mathrm{~S}_{3}\right)$, and layerstructured chalcogenides $\left(\mathrm{MoS}_{2}\right.$ and $\left.\mathrm{SnSe}\right)$ form another class of attractive electrode material for flexible supercapacitors because of their chemically rich surface area to host redox reactions (Feng et al., 2011; Cao et al., 2013; Ratha and Rout, 2013; Jiang et al., 2014; Peng et al., 2014; Wei et al., 2014; Zhang C. et al., 2014). Ternary and higher-order chalcogenide-based materials have recently been successfully synthesized owing to tremendous advances in wet-chemical synthesis techniques (Ramasamy et al., 2014b, 2015). These materials are further appealing for supercapacitor electrodes as they contain different metal ions to facilitate rich redox reactions and the tunable gap between the layers can host a wide range of ions from the electrolyte to enhance the specific capacitance. For example, the $\mathrm{CuSbS}_{2}$ and $\mathrm{CuSbSe}_{\mathrm{x}} \mathrm{S}_{2-\mathrm{x}}$ mesocrystals provided exceptional cyclic stability at high current densities, making them attractive for fast charging applications (Ramasamy et al., 2014a,c).

There have been several works on metal molybdate heterostructures as they are cost-effective, environment-friendly, and show high electrochemical performance. Different morphologies and composition of molybdates e.g., three-dimensional $\mathrm{MnMoO}_{4} / \mathrm{CoMoO}_{4}$ hetero-structures, $\mathrm{CoMoO}_{4}$-graphene composite, hierarchical $\mathrm{NiMoO}_{4}$ nanospheres, and $\mathrm{NiMoO}_{4}$ nanowires have been investigated (Mai et al., 2011; Cai et al., 2013; Xia X. et al., 2013). In $\mathrm{NiMoO}_{4}$, it was observed that the spherical morphology facilitated increased capacitance owing to its high surface area and electrical conductivity. The effect of morphology was investigated in detail with shape-controlled $\mathrm{CoMoO}_{4}$ nanostructures (e.g., cauliflower, brick-like, and spherical) (Candler et al., 2015). The charge storage capacity of the material is dependent on its morphology. The flexible supercapacitor device fabricated with the shape-controlled cobalt molybdate electrodes exhibited improved stability with an increase in number of cyclic CV performance. The device was also found to be an attractive candidate for high-temperature 


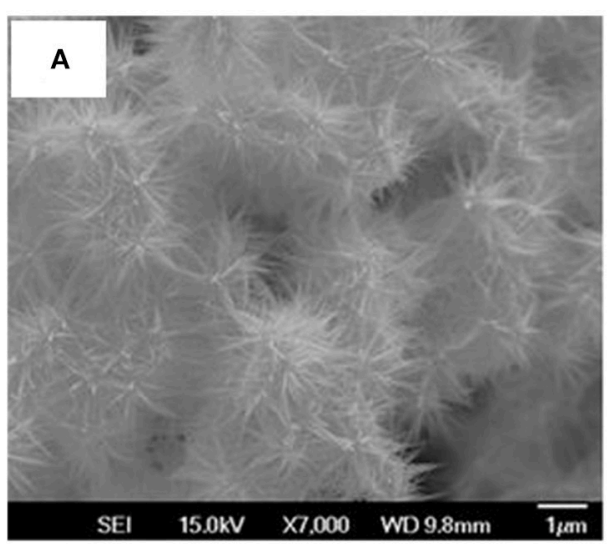

$\mathbf{B}$
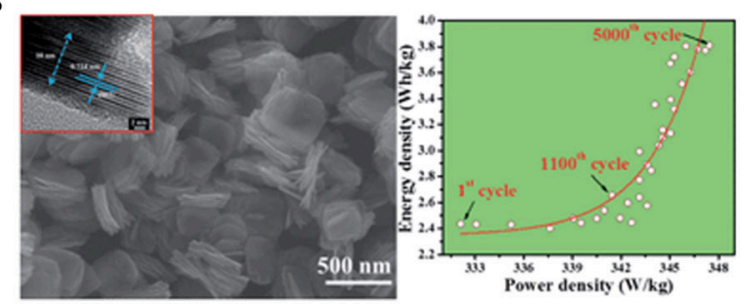

$\mathrm{CuSbS}_{2}$
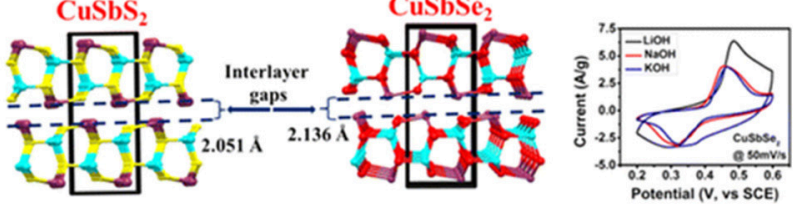

C
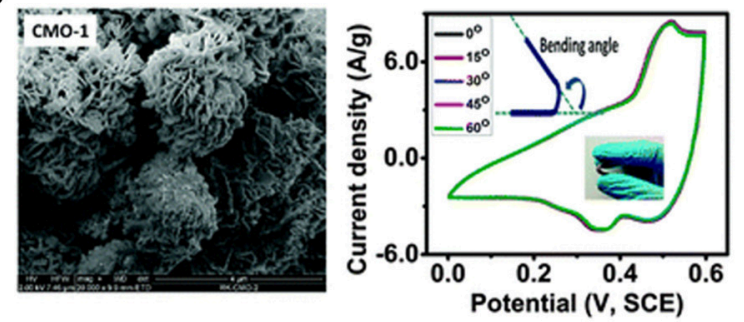

FIGURE 2 | Advanced pseudocapacitive materials for supercapacitor electrodes. (A) scanning electron microscope (SEM) image of $\mathrm{NiCO}_{2} \mathrm{O}_{4}$ nanocrystals grown on nickel foam, an attractive electrode material for variable temperature operation; Copyright: Scientific Reports, (Gupta et al., 2015) (B) top, SEM image and power density of layered ternary sulfide $\mathrm{CuSbS}_{2}$ nanoplates; Copyright: Journal of Materials Chemistry A (Ramasamy et al., 2015) and bottom, CuSbSe 2 mesocrystals with controlled inter-layer gap; Copyright: Chemistry of Materials, (Ramasamy et al., 2014a) and (C) SEM image of $\mathrm{CoMoO}_{4}$ nanocrystals and CV curves at different bending angles of the flexible device; Copyright: New Journal of Chemistry (Candler et al., 2015).

supercapacitor operations. Figure 2 shows the new ternary metal oxide, higher order chalcogenide, and metal molybdate pseudocapacitive electrode materials synthesized.

In a recent breakthrough, Ko et al. reported a new ligandmediated layer-by-layer technique to assemble metal (Au) and metal oxide $(\mathrm{MnO})$ pseudocapacitive nanoparticles on flexible paper substrate to form supercapacitor electrodes (Ko et al., 2017). The device showed substantially high energy (15.1 $\mathrm{mWcm}^{-2}$ ) and power $\left(267.3 \mu \mathrm{Whcm}^{-2}\right)$ densities. The method is an improvement over conventional physical adsorption processes like dip coating, painting, Meyer rod coating, and dispensing-writing because it allows controlled loading of both the conducting polymer and the active materials onto the substrate. In another breakthrough report, a lamellar electrode material of vanadium nitride nanodots intercalated in carbon nanosheets has shown an ultrahigh volumetric capacitance $\left(1203.6 \mathrm{Fcm}^{-3}\right.$ at $1.1 \mathrm{Acm}^{-3}$; rate capability of $703.1 \mathrm{Fcm}^{-3}$ at $210 \mathrm{Acm}^{-3}$ ) that exceeds most carbon-transition metal oxide/nitride PCs known to date (Gao et al., 2015; Li et al., 2018). This vanadium nitride based electrode is a significant improvement over previous reports of vanadium nitride nanostructures with limited specific surface area and capacitive performance. Therefore, the type of material and assembly technique are two key parameters to achieve high performing charge storage in flexible PCs. Liu et al. recently developed a new oxidative chemical vapor deposition method for fabricating electrodes coated with pseudocapacitive poly $(3,4-$ ethylene dioxythiophene) polymer (Liu et al., 2017).

As seen from the literature review, one of the primary strategies to render the PCs flexible and lightweight for suitable operation has been to use a variety of cost-effective and ecofriendly flexible substrates (e.g., metals, carbon paper and foam, conventional paper, textile, sponge, and cable). Metal substrates have the merits of high electric conductivity and mechanical strength (Dubal and Holze, 2013a; Dubal et al., 2013; Jagadale et al., 2013). Flexible stainless steel has been one of the most widely used metal substrates to directly fabricate electroactive electrode materials such as $\mathrm{MnO}_{2}$ nanorod forests and shape-controlled $\mathrm{Ni}(\mathrm{OH})_{2}$ nanostructures (Gund et al., 2013; Santhanagopalan et al., 2013). Electrodeposition has been used to form $\mathrm{Co}(\mathrm{OH})_{2}$ nanoflake films on flexible stainless steel substrates (Chou et al., 2008). Facile chemical methods have also been reported for depositing stacked $\mathrm{Mn}_{3} \mathrm{O}_{4}$ nanosheets, $\mathrm{Mn}_{3} \mathrm{O}_{4}$ thin films, as well as nanostructured polyaniline electrode materials on flexible stainless steel substrates (Dhawale et al., 2011; Dubal et al., 2012; Dubal and Holze, 2013b). These stainless steel supercapacitors are highly promising in terms of long-term stability. Other metallic substrates, including $\mathrm{Al}, \mathrm{Ti}, \mathrm{Cu}$, and $\mathrm{Ni}$ foam, have also been successfully used to fabricate hierarchical and bendable supercapacitors with excellent cycling stability (Liu et al., 2010; Le et al., 2011; Lin et al., 2011; Yuan et al., 2011; Zhang et al., 2011; Kai et al., 2012; Kim et al., 2012; Wang et al., 2012, 2013; Zhou et al., 2012, 2013; Dorfler et al., 2013; Reit et al., 2013; Xia H. et al., 2013). Metal-supported flexible electrodes are however, opaque and less stretchable. Therefore, flexible plastic substrates are preferred in supercapacitor electrodes for touch-screen displays (Yu et al., 2010; Niu et al., 2013; Shi et al., 2013a; Chen et al., 2014; Hao et al., 2014). Flexible supercapacitor electrodes of graphene films supported on polyethylene terephthalate (PET), $\mathrm{MnO}_{2}$ nanosheets on indium tin oxide-PET substrates, or single-walled carbon nanotubes on polydimethylsiloxane and polyaniline substrates have proved to be highly promising for transparent electronics in terms of capacitance and stretchability. However, plastic substrates 
are limited in electrical conductivity. Paper-based flexible supercapacitors, being lightweight, bendable, transparent, and easily processable are attractive alternatives for electronic screens of portable devices (e.g., mobile phones, digital cameras, and laptops). In this regard, both free-standing electrodes such as carbon nanotube (CNT)-paper composites and deposition of PCs on recyclable paper substrates have been successfully investigated. The hierarchical macroporous and networkfree morphology in flexible sponge substrates facilitate high liquid absorption, increased surface area, continuous coating, and enhanced interaction between electrodes and electrolyte. Symmetrical flexible supercapacitors consisting of CNT sponge assembly and synthesized via chemical vapor deposition have been reported to show excellent cyclic stability (Li et al., 2013). In addition, $\mathrm{Fe}_{3} \mathrm{O}_{4}$ and $\mathrm{MnO}_{2}$ are attractive $\mathrm{PC}$ materials to further increase the energy density of carbonaceous sponge substrates (Chen et al., 2011; Wu et al., 2013). Textile substrates like cotton cloth, polyester microfiber twill, and carbon fabric are synthesized from natural or synthetic fibers via weaving, pressing, knitting, or felting. These substrates have the advantage of high stretchability, lightweight, three-dimensional open-pore structure, good mechanical strength, and low cost compared to other substrates for flexible supercapacitors. Stretchable textile electrodes have been fabricated by impregnating single-walled carbon nanotubes into cotton cloth or porous carbon materials into woven cotton/polyester textile (Hu et al., 2010; Jost et al., 2011). To further increase the electrochemical capacitance, metal oxide nanoparticles (e.g., $\mathrm{MnO}_{2}$ ) have been coated on carbon fiber-based textile substrates to form the flexible electrodes (Yuan et al., 2012; Zhao et al., 2013; Tao et al., 2014; Yang et al., 2014a,b). The electrochemically active material coating is the primary contributor for the total capacitance of textile-based flexible electrode, since textiles have inherently low capacitance. Therefore, a flexible activated carbon felt $/ \mathrm{MnO}_{2} / \mathrm{CNT}$ assembly have recently been fabricated to obtain enhanced capacitance and high performance (Dong et al., 2016b). In addition, metal organic frameworks (MOFs), a class of co-ordination polymers having high specific surface area and controllable pore size to anchor the active materials are being used to address the limitations of carbon textile substrates (Xu et al., 2017; Liu et al., 2018; Zhao et al., 2018). The MOFs can be applied in three ways for flexible supercapacitors, directly as an electrode material, as a composite electrode, or as a flexible substrate for active electrode materials (Zhao et al., 2018). Polyoxometalates are another class of porous substrates with novel electronic properties, robust structure, and capability to behave like an acid during synthesis owing to their metal-oxygen clusters. The polyoxometalates have recently been used to significantly improve the electrical conductivity of low-cost electrode materials like $\mathrm{MnO}_{2}$ nanoparticles (Wang et al., 2018). Another emerging direction in flexible substrates is biomass-derived substrates and wood substrates (Lv et al., 2015; Herou et al., 2018). Wood transverse section slice is a promising candidate for flexible substrates as it shows excellent hydrophilic property, but does not require any harsh and expensive chemical processing steps involved in the preparation of other substrates (e.g., cellulosic paper). Recently, a new anode material of low crystalline $\mathrm{FeOOH}$ nanoparticles coated on carbon fiber cloth has achieved both high energy (104 $\left.\mathrm{Whkg}^{-1}\right)$ and power (1.27 $\mathrm{kWkg}^{-1}$ ) densities (Owusu et al., 2017).

EDLCs primarily use carbon materials as electrode (Hu et al., 2010; Dong et al., 2016a). The single carbon electrodes in EDLCs are made of carbon networks (e.g., carbon fabric, cloth, film, coating, paper, or textile) fabricated from one dimensional (1D) carbon nanotubes or carbon fibers and/or two dimensional (2D) graphene or graphite sheets (Weng et al., 2011; Chen and Dai, 2014). Different fabrication techniques like weaving, chemical vapor deposition, filtration, printing, evaporation, or dip-drying are used to form carbon networks by van der Waals interaction or hydrogen bonding of carbon particles (Cheng and Liu, 2013; Tan et al., 2017). Carbon fabric, a highly suitable carbon network for flexible supercapacitors in terms of strength, stiffness, and flexibility is primarily manufactured by plain, satin, or twill weaving technique (Cheng and Liu, 2013; Qian et al., 2013; Dong et al., 2016a). A stable dispersion of carbon material and ligand such as sodium dodecylbenzene sulfonate in a suitable solvent serves as the starting agent for the other types of carbon network including carbon film, paper, or textile. Carbon films can be formed using chemical vapor deposition to assemble singlewalled carbon nanotubes on polydimethylsiloxane substrates. They can also be formed by ink-jet printing or spin-coating the carbon materials on flexible plastic or paper substrates. Paper forms a highly suitable substrate due to its high porosity and surface area, but large pore sizes can cause the carbon nanostructures to penetrate into the substrate (Lee et al., 2017) (Pushparaj et al., 2007). Applying polyvinylidene fluoride coating on the substrate has been used as a facile pre-treatment method to facilitate maximum adhesion of carbon electrode materials to the porous paper substrate while maintaining the electrical conductivity. Carbon paper, in contrast, is prepared by the filtration or evaporation techniques. A dipping-drying method similar to the cloth dyeing process is essentially used to fabricate carbon textiles. In a typical synthesis, the fabric is dipped in the pre-formed dye solution containing carbon materials before drying the solvent from the fabric to form the electrode. In addition to the electrode material, an ultrathin in-plane geometry of the electrode is seen to facilitate higher interaction of the electrode/electrolyte for EDLCs as compared to a planar stacked geometry (Chen and Dai, 2014). Vertical alignment of the active electrode material on the substrate has also been known to significantly enhance the capacitance (Izadi-Najafabadi et al., 2010; Eftekhari, 2018). Investigating the underlying mechanism of the role played by alignment in graphene supercapacitors will be a key future direction in increasing the energy density in EDLCs and building ultrafast supercapacitors (Eftekhari, 2018). Recently, ionic liquids have been successfully investigated as solvent/electrolyte for EDLCs due to their attractive properties like high ionic conductivity, a wide range of electrochemical potential, and excellent moisture stability, and relatively low volatility (Lehtimaki et al., 2015; Lorenzo and Srinivasan, 2018). In addition to graphene and carbon based EDLCs, black phosphorus, a two-dimensional layered and p-type direct bandgap semiconducting electrode material has recently coupled high power density with high energy density in EDLCs (Yang et al., 2017). 


\section{CONCLUSION}

In this review, we have summarized the recent progress in the development of novel electrode materials of high specific supercapacitance for both EDLC and PC flexible supercapacitors. Ternary and higher order nanostructures of metal oxides, layered structure transition metal chalcogenides, metal molybdates, vanadium nitride, and polyoxometalate- $\mathrm{MnO}_{2}$ have proved attractive for PC electrodes. The shape-controlled $\mathrm{CoMoO}_{4}$ nanostructure $\mathrm{PC}$ electrodes are promising in high-temperature operation. Advances in EDLC electrodes such as new fabrication techniques and use of ionic liquids as solvent/electrolytes have been described in the review. In addition, we have summarized the emerging advances in low-cost flexible substrates in terms of material categories (e.g., metal, paper, carbon-paper, sponges, textiles, or cable-type substrates) and their corresponding advantages and limitations.

In brief, flexible supercapacitors are highly attractive for their excellent power density and the major challenges in the technology lie in their low energy density and high production cost. Therefore, one of the future directions in flexible supercapacitors is combining commonly found EDLC materials with cost-effective PC active materials to form novel hybrid electrodes. Recently, a significant increase in energy density $\left(104.3 \mathrm{Whkg}^{-1}\right)$ has been achieved with a hybrid supercapacitor composed of an capacitive dominant anode of iron oxide hydroxide nanoparticles grown on flexible carbon fiber cloth and a $\mathrm{PC} \mathrm{NiMoO}_{4}$ cathode, while maintaining exceptional stability and power density (Owusu et al., 2017). Another scientific thrust is to develop solution-based processes and robust fabrication routes for large-scale manufacturing of flexible supercapacitors. Novel electrolytes and electrode materials are also being investigated to enable high-temperature operation of

\section{REFERENCES}

Cai, D., Wang, D., Liu, B., Wang, Y., Liu, Y., Wang, L., et al. (2013). Comparison of the electrochemical performance of $\mathrm{NiMoO}_{4}$ nanorods and hierarchical nanospheres for supercapacitor applications. ACS Appl. Mater. Interfaces 5, 12905-12910. doi: 10.1021/am403444v

Candler, J., Elmore, T., Gupta, B. K., Dong, L., Palchoudhury, S., and Gupta, R. K. (2015). New insight into high-temperature driven morphology reliant $\mathrm{CoMoO}_{4}$ flexible supercapacitors. New J. Chem. 39, 6108-6116. doi: 10.1039/C5NJ00446B

Cao, L., Yang, S., Gao, W., Liu, Z., Gong, Y., Ma, L., et al. (2013). Direct laser-patterned micro-supercapacitors from paintable MoS2 films. Small 9, 2905-2910. doi: 10.1002/smll.201203164

Chee, W., Lim, H., Zainal, Z., Huang, N., Harrison, I., and Andou, Y. (2016). Flexible graphene-based supercapacitors: a review. J. Phys. Chem. C 120, 4153-4172. doi: 10.1021/acs.jpcc.5b10187

Chen, T., and Dai, L. (2014). Flexible supercapacitors based on carbon nanomaterials. J. Mater. Chem. A 2, 10756-10775. doi: 10.1039/c4ta00567h

Chen, W., Rakhi, R. B., Hu, L., Xie, X., Cui, Y., and Alshareef, H. N. (2011). High-performance nanostructured supercapacitors on a sponge. Nano Lett. 11, 5165-5172. doi: 10.1021/nl2023433

Chen, X., Lin, H., Chen, P., Guan, G., Deng, J., and Peng, H. (2014). Smart, stretchable supercapacitors. Adv. Mater. 26, 4444-4445. doi: 10.1002/adma.201400842 the flexible supercapacitors. Therefore, flexible supercapacitors is a rapidly advancing and environment-friendly technology for energy storage. It is envisioned to both serve as a primary energy storage and in combination with LIBs.

\section{AUTHOR CONTRIBUTIONS}

SP was responsible for writing and formatting the article. KR wrote and communicated the manuscript. RG and AG supervised and wrote the manuscript.

\section{FUNDING}

2018 Center of Excellence for Applied Computational Science competition, University of Tennessee at Chattanooga.

\section{ACKNOWLEDGMENTS}

The authors acknowledge the University of Tennessee Chattanooga. Research reported in this publication was partially supported by the 2018 Center of Excellence for Applied Computational Science competition. We gratefully acknowledge UA-MINT Center for additional support. This work was performed, in part, at the Center for Integrated Nanotechnologies, an Office of Science User Facility operated for the U. S. Department of Energy (DOE) Office of Science by Los Alamos National Laboratory (Contract DE-AC52-06NA25396) and Sandia National Laboratories (Contract DE-NA-0003525). RG expresses his sincere acknowledgment to the Polymer Chemistry Program and Kansas Polymer Research Center, Pittsburg State University for providing financial and research support.

Cheng, Y., and Liu, J. (2013). Carbon nanomaterials for flexible energy storage. Mater. Res. Lett. 1, 175-192. doi: 10.1080/21663831.2013.808712

Chou, S., Wang, J., Liu, H., and Dou, S. (2008). Electrochemical deposition of porous $\mathrm{Co}(\mathrm{OH})(2)$ nanoflake films on stainless steel mesh for flexible supercapacitors. J. Electrochem. Soc. 155, A926-A929. doi: 10.1149/1.2988739

Dhawale, D., Vinu, A., and Lokhande, C. D. (2011). Stable nanostructured polyaniline electrode for supercapacitor application. Electrochim. Acta 56, 9482-9487. doi: 10.1016/j.electacta.2011.08.042

Dong, L., Xu, C., Li, Y., Huang, Z., Kang, F., Yang, Q., et al. (2016a). Flexible electrodes and supercapacitors for wearable energy storage: a review by category. J. Mater. Chem. A 4, 4659-4685. doi: 10.1039/C5TA10582J

Dong, L., Xu, C., Li, Y., Pan, Z., Liang, G., Zhou, E., et al. (2016b). Breathable and wearable energy storage based on highly flexible paper electrodes. Adv. Mater. 28, 9313-9319. doi: 10.1002/adma.201602541

Dorfler, S., Felhosi, I., Marek, T., Thieme, S., Althues, H., Nyikos, L., et al. (2013). High power supercap electrodes based on vertical aligned carbon nanotubes on aluminum. J. Power Sources 227, 218-228. doi: 10.1016/j.jpowsour.2012.11.068

Dubal, D., and Holze, R. (2013a). All-solid-state flexible thin film supercapacitor based on $\mathrm{Mn}_{3} \mathrm{O}_{4}$ stacked nanosheets with gel electrolyte. Energy 51, 407-412. doi: 10.1016/j.energy.2012.11.021

Dubal, D., and Holze, R. (2013b). Self-assembly of stacked layers of $\mathrm{Mn}_{3} \mathrm{O}_{4}$ nanosheets using a scalable chemical strategy for enhanced, flexible, electrochemical energy storage. J. Power Sources 238, 274-282. doi: 10.1016/j.jpowsour.2013.01.198 
Dubal, D., Jagadale, A., and Lokhande, C. (2012). Big as well as light weight portable, $\mathrm{Mn}_{3} \mathrm{O}_{4}$ based symmetric supercapacitive devices: fabrication, performance evaluation and demonstration. Electrochim. Acta 80, 160-170. doi: 10.1016/j.electacta.2012.06.124

Dubal, D., Kim, J., Kim, Y., Holze, R., and Kim, W. (2013). Demonstrating the highest supercapacitive performance of branched $\mathrm{MnO}_{2}$ nanorods grown directly on flexible substrates using controlled chemistry at ambient temperature. Energy Technol. 1, 125-130. doi: 10.1002/ente.201200040

Eftekhari, A. (2018). The mechanism of ultrafast supercapacitors. J. Mater. Chem. A 6, 2866-2876. doi: 10.1039/C7TA10013B

Endo, M., Takeda, T., Kim, Y., Koshiba, K., and Ishii, K. (2001). High power electric double layer capacitor (EDLC's); from operating principle to pore size control in advanced activated carbons. Carbon Lett. 1, 117-128.

Fan, Z., Yan, J., Wei, T., Zhi, L., Ning, G., Li, T., et al. (2011). Asymmetric supercapacitors based on graphene/MnO2 and activated carbon nanofiber electrodes with high power and energy density. Adv. Funct. Mater. 21, 2366-2375. doi: 10.1002/adfm.201100058

Feng, J., Sun, X., Wu, C., Peng, L., Lin, C., Hu, S., et al. (2011). Metallic few-layered $\mathrm{VS}_{2}$ ultrathin nanosheets: high two-dimensional conductivity for in-plane supercapacitors. J. Am. Chem. Soc. 133, 17832-17838. doi: 10.1021/ja207176c

Gao, B., Li, X., Guo, X., Zhang, X., Peng, X., Wang, L., et al. (2015). Nitrogendoped carbon encapsulated mesoporous vanadium nitride nanowires as selfsupported electrodes for flexible all-solid-state supercapacitors. Adv. Mater. Interfaces 2:1500211. doi: 10.1002/admi.201500211

Gund, G., Dubal, D., Jambure, S., Shinde, S., and Lokhande, C. (2013). Temperature influence on morphological progress of $\mathrm{Ni}(\mathrm{OH})(2)$ thin films and its subsequent effect on electrochemical supercapacitive properties. J. Mater. Chem. A 1, 4793-4803. doi: 10.1039/c3ta00024a

Gupta, R. K., Candler, J., Palchoudhury, S., Ramasamy, K., and Gupta, B. K. (2015). Flexible and high performance supercapacitors based on $\mathrm{NiCo}(2) \mathrm{O}(4)$ for wide temperature range applications. Sci. Rep. 5:15265. doi: 10.1038/srep15265

Hao, C., Wen, F., Xiang, J., Wang, L., Hou, H., Su, Z., et al. (2014). Controlled incorporation of $\mathrm{Ni}(\mathrm{OH})(2)$ nanoplates into flowerlike $\mathrm{MoS}_{2}$ nanosheets for flexible all-solid-state supercapacitors. Adv. Funct. Mater. 24, 6700-6707. doi: 10.1002/adfm.201401268

Herou, S., Schlee, P., Jorge, A., and Titirici, M. (2018). Biomass-derived electrodes for flexible supercapacitors. Curr. Opin. Green Sustain. Chem. 9, 18-24. doi: 10.1016/j.cogsc.2017.10.005

$\mathrm{Hu}, \mathrm{C}$., and Chen, W. (2004). Effects of substrates on the capacitive performance of $\mathrm{RuOx}$ center dot $\mathrm{nH}(2) \mathrm{O}$ and activated carbonRuOx electrodes for supercapacitors. Electrochim. Acta 49, 3469-3477. doi: 10.1016/j.electacta.2004.03.017

Hu, L., Pasta, M., La Mantia, F. L., Cui, L., Jeong, S., Deshazer, H. D., et al. (2010). Stretchable, porous, and conductive energy textiles. Nano Lett. 10, 708-714. doi: $10.1021 / \mathrm{nl} 903949 \mathrm{~m}$

Huang, L., Chen, D., Ding, Y., Feng, S., Wang, Z. L., and Liu, M. (2013). Nickelcobalt hydroxide nanosheets coated on $\mathrm{NiCo}_{2} \mathrm{O}_{4}$ nanowires grown on carbon fiber paper for high-performance pseudocapacitors. Nano Lett. 13, 3135-3139. doi: $10.1021 / \mathrm{nl} 401086 \mathrm{t}$

Izadi-Najafabadi, A., Yasuda, S., Kobashi, K., Yamada, T., Futaba, D. N., Hatori, H., et al. (2010). Extracting the full potential of single-walled carbon nanotubes as durable supercapacitor electrodes operable at $4 \mathrm{~V}$ with high power and energy density. Adv. Mater. 22, E235-E236. doi: 10.1002/adma.200904349

Jagadale, A., Kumbhar, V., Dhawale, D., and Lokhande, C. (2013). Performance evaluation of symmetric supercapacitor based on cobalt hydroxide $\mathrm{Co}(\mathrm{OH})(2)$ thin film electrodes. Electrochim. Acta 98, 32-38. doi: 10.1016/j.electacta.2013.02.094

Jiang, Z., Lu, W., Li, Z., Ho, K., Li, X., Jiao, X., et al. (2014). Synthesis of amorphous cobalt sulfide polyhedral nanocages for high performance supercapacitors. $J$. Mater. Chem. A 2, 8603-8606. doi: 10.1039/C3TA14430E

Jost, K., Perez, C. R., McDonough, J. K., Presser, V., Heon, M., Dion, G., et al. (2011). Carbon coated textiles for flexible energy storage. Energy Environ. Sci. 4, 5060-5067. doi: 10.1039/clee02421c

Kai, K., Kobayashi, Y., Yamada, Y., Miyazaki, K., Abe, T., Uchimoto, Y., et al. (2012). Electrochemical characterization of single-layer $\mathrm{MnO}_{2}$ nanosheets as a high-capacitance pseudocapacitor electrode. J. Mater. Chem. 22, 14691-14695. doi: $10.1039 / \mathrm{c} 2 \mathrm{jm} 31080 \mathrm{e}$
Khomenko, V., Raymundo-Pinero, E., and Beguin, F. (2006). Optimisation of an asymmetric manganese oxide/activated carbon capacitor working at $2 \mathrm{~V}$ in aqueous medium. J. Power Sources 153, 183-190. doi: 10.1016/j.jpowsour.2005.03.210

Kim, B., Chung, H., and Kim, W. (2012). High-performance supercapacitors based on vertically aligned carbon nanotubes and nonaqueous electrolytes. Nanotechnology 23:155401. doi: 10.1088/0957-4484/23/15/ 155401

Ko, Y., Kwon, M., Bae, W. K., Lee, B., Lee, S. W., and Cho, J. (2017). Flexible supercapacitor electrodes based on real metal-like cellulose papers. Nat. Commun. 8:536. doi: 10.1038/s41467-017-00550-3

Le, L., Ervin, M., Qiu, H., Fuchs, B., and Lee, W. (2011). Graphene supercapacitor electrodes fabricated by inkjet printing and thermal reduction of graphene oxide. Electrochem. Commun. 13, 355-358. doi: 10.1016/j.elecom.2011.01.023

Lee, D., Cho, Y., Song, H., Chun, S., Park, S., Choi, D., et al. (2017). Coffee-driven green activation of cellulose and its use for all-paper flexible supercapacitors. ACS Appl. Mater. Interfaces 9, 22568-22577. doi: 10.1021/acsami.7b05712

Lee, H. Y., and Goodenough, J. B. (1999). Supercapacitor behavior with $\mathrm{KCl}$ electrolyte. J. Solid State Chem. 144, 220-223. doi: 10.1006/jssc.1998.8128

Lehtimaki, S., Suominen, M., Damlin, P., Tuukkanen, S., Kvarnstrom, C., and Lupo, D. (2015). Preparation of supercapacitors on flexible substrates with electrodeposited PEDOT/graphene composites. ACS Appl. Mater. Interfaces 7, 22137-22147. doi: 10.1021/acsami.5b05937

Li, M., Pan, F., Choo, E., Lv, Y., Chen, Y., and Xue, J. (2016). Designed construction of a graphene and iron oxide freestanding electrode with enhanced flexible energy-storage performance. ACS Appl. Mater. Interfaces 8, 6972-6981. doi: 10.1021/acsami.5b10853

Li, P., Kong, C., Shang, Y., Shi, E., Yu, Y., Qian, W., et al. (2013). Highly deformation-tolerant carbon nanotube sponges as supercapacitor electrodes. Nanoscale 5, 8472-8479. doi: 10.1039/c3nr01932b

Li, Q., Chen, Y., Zhang, J., Tian, W., Wang, L., Ren, Z., et al. (2018). Spatially confined synthesis of vanadium nitride nanodots intercalated carbon nanosheets with ultrahigh volumetric capacitance and long life for flexible supercapacitors. Nano Energy 51, 128-136. doi: 10.1016/j.nanoen.2018.06.053

Lim, Y., Tan, Y., Lim, H., Huang, N., Tan, W., Yarmo, M., et al. (2014). Potentiostatically deposited polypyrrole/graphene decorated nano-manganese oxide ternary film for supercapacitors. Ceram. Inter. 40, 3855-3864. doi: 10.1016/j.ceramint.2013.08.026

Lin, R., Taberna, P., Fantini, S., Presser, V., Perez, C., Malbosc, F., et al. (2011). Capacitive energy storage from -50 to $100^{\circ} \mathrm{C}$ using an ionic liquid electrolyte. J. Phys. Chem. Lett. 2, 2396-2401. doi: 10.1021/jz201065t

Liu, A., Kovacik, P., Peard, N., Tian, W., Goktas, H., Lau, J., et al. (2017). Monolithic flexible supercapacitors integrated into single sheets of paper and membrane via vapor printing. Adv. Mater. 29:1606091. doi: 10.1002/adma.201606091

Liu, J., Essner, J., and Li, J. (2010). Hybrid supercapacitor based on coaxially coated manganese oxide on vertically aligned carbon nanofiber arrays. Chem. Mater. 22, 5022-5030. doi: 10.1021/cm101591p

Liu, X., Guan, C., Hu, Y., Zhang, L., Elshahawy, A., and Wang, J. (2018). 2D metalorganic frameworks derived nanocarbon arrays for substrate enhancement in flexible supercapacitors. Small 14:e1702641. doi: 10.1002/smll.201702641

Lorenzo, M., and Srinivasan, G. (2018). Durable flexible supercapacitors utilizing the multifunctional role of ionic liquids. Energy Technol. 6, 196-204. doi: 10.1002/ente.201700407

Lv, S., Fu, F., Wang, S., Huang, J., and Hu, L. (2015). Eco-friendly woodbased solid-state flexible supercapacitors from wood transverse section slice and reduced graphene oxide. Electron. Mater. Lett. 11, 633-642. doi: 10.1007/s13391-015-5023-z

Mai, L., Yang, F., Zhao, Y., Xu, X., Xu, L., and Luo, Y. (2011). Hierarchical $\mathrm{MnMoO}_{4} / \mathrm{CoMoO}_{4}$ heterostructured nanowires with enhanced supercapacitor performance. Nat. Commun. 2:381. doi: 10.1038/ncomms1387

Miller, J. R., and Simon, P. (2008). Materials science - electrochemical capacitors for energy management. Science 321, 651-652. doi: 10.1126/science.1158736

Mitchell, E., Jimenez, A., Gupta, R. K., Gupta, B. K., Ramasamy, K., Shahabuddin, M., et al. (2015). Ultrathin porous hierarchically textured $\mathrm{NiCo}_{2} \mathrm{O}_{4}$-graphene oxide flexible nanosheets for high-performance supercapacitors. New J. Chem. 39, 2181-2187. doi: 10.1039/C4NJ02110J 
Niu, Z., Dong, H., Zhu, B., Li, J., Hng, H., Zhou, W., et al. (2013). Highly stretchable, integrated supercapacitors based on single-walled carbon nanotube films with continuous reticulate architecture. Adv. Mater. 25, 1058-1064. doi: 10.1002/adma.201204003

Oh, S. H., and Nazar, L. F. (2010). Direct synthesis of electroactive mesoporous hydrous crystalline $\mathrm{RuO}_{2}$ templated by a cationic surfactant. J. Mater. Chem. 20, 3834-3839. doi: 10.1039/b926734d

Owusu, K. A., Qu, L., Li, J., Wang, Z., Zhao, K., Yang, C., et al. (2017). Lowcrystalline iron oxide hydroxide nanoparticle anode for high-performance supercapacitors. Nat. Commun. 8:14264. doi: 10.1038/ncomms14264

Peng, S., Li, L., Tan, H., Cai, R., Shi, W., Li, C., et al. (2014). $\mathrm{MS}_{2}(\mathrm{M}=$ $\mathrm{Co}$ and $\mathrm{Ni}$ ) hollow spheres with tunable interiors for high-performance supercapacitors and photovoltaics. Adv. Func. Mater. 24, 2155-2162. doi: $10.1002 /$ adfm. 201303273

Pushparaj, V., Shaijumon, M., Kumar, A., Murugesan, S., Ci, L., Vajtai, R., et al. (2007). Flexible energy storage devices based on nanocomposite paper. Proc. Natl. Acad. Sci. U. S. A. 104, 13574-13577. doi: 10.1073/pnas.0706508104

Qian, H., Kucernak, A. R., Greenhalgh, E. S., Bismarck, A., and Shaffer, M. S (2013). Multifunctional structural supercapacitor composites based on carbon aerogel modified high performance carbon fiber fabric. ACS Appl. Mater. Interfaces 5, 6113-6122. doi: 10.1021/am400947j

Ramasamy, K., Gupta, R. K., Palchoudhury, S., Ivanov, S., and Gupta, A. (2014a). Layer-structured copper antimony chalcogenides $\left(\mathrm{CuSbSe}_{\mathrm{x}} \mathrm{S}_{2-\mathrm{x}}\right)$ : stable electrode materials for supercapacitors. Chem. Mater. 27, 379-386. doi: $10.1021 / \mathrm{cm} 5041166$

Ramasamy, K., Gupta, R. K., Sims, H., Palchoudhury, S., Ivanov, S., and Gupta, A. (2015). Layered ternary sulfide CuSbS2 nanoplates for flexible solid-state supercapacitors. J. Mater. Chem. A. 3, 13263-13274. doi: 10.1039/C5TA03193A

Ramasamy, K., Sims, H., Butler, W. H., and Gupta, A. (2014b). Selective nanocrystal synthesis and calculated electronic structure of all four phases of copper-antimony-sulfide. Chem. Mater. 26, 2891-2899. doi: $10.1021 / \mathrm{cm} 5005642$

Ramasamy, K., Sims, H., Butler, W. H., and Gupta, A. (2014c). Mono-, few-, and multiple layers of copper antimony sulfide $\left(\mathrm{CuSbS}_{2}\right)$ : a ternary layered sulfide. J. Am. Chem. Soc. 136, 1587-1598. doi: 10.1021/ja411748g

Ratha, S., and Rout, C. S. (2013). Supercapacitor electrodes based on layered tungsten disulfide-reduced graphene oxide hybrids synthesized by a facile hydrothermal method. ACS Appl. Mater. Interfaces 5, 11427-11433. doi: 10.1021/am403663f

Reit, R., Nguyen, J., and Ready, W. (2013). Growth time performance dependence of vertically aligned carbon nanotube supercapacitors grown on aluminum substrates. Electrochim. Acta 91, 96-100. doi: 10.1016/j.electacta.2012.12.058

Santhanagopalan, S., Balram, A., and Meng, D. (2013). Scalable high-power redox capacitors with aligned nanoforests of crystalline $\mathrm{MnO}_{2}$ nanorods by high voltage electrophoretic deposition. ACS Nano 7, 2114-2125. doi: $10.1021 / \mathrm{nn} 3044462$

Shi, S., Xu, C., Yang, C., Chen, Y., Liu, J., and Kang, F. (2013a). Flexible asymmetric supercapacitors based on ultrathin two-dimensional nanosheets with outstanding electrochemical performance and aesthetic property. Sci. Rep. 3:2598. doi: 10.1038/srep02598

Shi, S., Xu, C. J., Yang, C., Li, J., Du, H., Li, B., et al. (2013b). Flexible supercapacitors. Particuology 11, 371-377. doi: 10.1016/j.partic.2012.12.004

Tan, R., Reeves, S., Hashemi, N., Thomas, D., Kavak, E., Montazami, R., et al. (2017). Graphene as a flexible electrode: review of fabrication approaches. J. Mater. Chem. A 5, 17777-17803. doi: 10.1039/C7TA05759H

Tao, J., Liu, N., Li, L., and Gao, Y. (2014). Hierarchical nanostructures of polypyrrole@ $\mathrm{MnO}_{2}$ composite electrodes for high performance solid-state asymmetric supercapacitors. Nanoscale 6, 2922-2928. doi: 10.1039/c3nr05845j

Wang, Q., Wang, X., Liu, B., Yu, G., Hou, X., Chen, D., et al. (2013). $\mathrm{NiCo}_{2} \mathrm{O}_{4}$ nanowire arrays supported on $\mathrm{Ni}$ foam for high-performance flexible all-solidstate supercapacitors. J. Mater. Chem. A 1, 2468-2473. doi: 10.1039/c2ta01283a

Wang, X., Liu, H., Chen, X., Evans, D., and Yang, W. (2012). Fabrication of manganese dioxide nanosheet-based thin-film electrode and its electrochemical capacitance performance. Electrochim. Acta 78, 115-121. doi: 10.1016/j.electacta.2012.05.154

Wang, Y., Li, S., Hsiao, S., Liao, W., Chen, P., Yang, S., et al. (2014). Integration of tailored reduced graphene oxide nanosheets and electrospun polyamide- 66 nanofabrics for a flexible supercapacitor with high-volume- and high-areaspecific capacitance. Carbon 73, 87-98. doi: 10.1016/j.carbon.2014.02.043

Wang, Z., Gu, J., Li, S., Zhang, G., Zhong, J., Fan, X., et al. (2018). Onestep polyoxometalates-assisted synthesis of manganese dioxide for asymmetric supercapacitors with enhanced cycling lifespan. ACS Sustain. Chem. Eng. 7, 258-264. doi: 10.1021/acssuschemeng.8b03072

Wei, W., Mi, L., Gao, Y., Zheng, Z., Chen, W., and Guan, X. (2014). Partial ion-exchange of nickel-sulfide-derived electrodes for high performance supercapacitors. Chem. Mater. 26, 3418-3426. doi: 10.1021/cm5006482

Weng, Z., Su, Y., Wang, D., Li, F., Du, J., and Cheng, H. (2011). Graphenecellulose paper flexible supercapacitors. Adv. Energy Mater. 1, 917-922. doi: 10.1002/aenm.201100312

Winter, M., and Brodd, R. J. (2004). What are batteries, fuel cells, and supercapacitors? Chem. Rev. 104, 4245-4269. doi: 10.1021/cr020730k

Wu, X. L., Wen, T., Guo, H. L., Yang, S., Wang, X., and Xu, A. W. (2013). Biomassderived sponge-like carbonaceous hydrogels and aerogels for supercapacitors. ACS Nano 7, 3589-3597. doi: 10.1021/nn400566d

Xia, H., Zhu, D., Luo, Z., Yu, Y., Shi, X., Yuan, G., et al. (2013). Hierarchically structured $\mathrm{Co}_{3} \mathrm{O}_{4} @ \mathrm{Pt} @ \mathrm{MnO}_{2}$ nanowire arrays for highperformance supercapacitors. Sci. Rep. 3:2978. doi: 10.1038/srep02978

Xia, X., Lei, W., Hao, Q., Wang, W., and Wang, X. (2013). Onestep synthesis of $\mathrm{CoMoO}_{4} /$ graphene composites with enhanced electrochemical properties for supercapacitors. Electrochim. Acta 99, 253-261. doi: 10.1016/j.electacta.2013.03.131

Xu, X., Tang, J., Qian, H., Hou, S., Bando, Y., Hossain, M., et al. (2017). Three-dimensional networked metal-organic frameworks with conductive polypyrrole tubes for flexible supercapacitors. ACS Appl. Mater. Interfaces 9, 38737-38744. doi: 10.1021/acsami.7b09944

Yang, B., Hao, C., Wen, F., Wang, B., Mu, C., Xiang, J., et al. (2017). Flexible black-phosphorus nanoflake/carbon nanotube composite paper for highperformance all-solid-state supercapacitors. ACS Appl. Mater. Interfaces 9, 44478-44484. doi: 10.1021/acsami.7b13572

Yang, P., Ding, Y., Lin, Z., Chen, Z., Li, Y., Qiang, P., et al. (2014a). Low-cost high-performance solid-state asymmetric supercapacitors based on $\mathrm{MnO}_{2}$ nanowires and $\mathrm{Fe}_{2} \mathrm{O}_{3}$ nanotubes. Nano Lett. 14, 731-736. doi: $10.1021 / \mathrm{nl} 404008 \mathrm{e}$

Yang, P., Li, Y., Lin, Z., Ding, Y., Yue, S., Wong, C., et al. (2014b). Worm-like amorphous $\mathrm{MnO}_{2}$ nanowires grown on textiles for high-performance flexible supercapacitors. J. Mater. Chem. A 2, 595-599. doi: 10.1039/C3TA14275B

Yu, A., Roes, I., Davies, A., and Chen, Z. (2010). Ultrathin, transparent, and flexible graphene films for supercapacitor application. Appl. Phys. Lett. 96:253105. doi: 10.1063/1.3455879

Yuan, C., Yang, L., Hou, L., Shen, L., Zhang, F., Li, D., et al. (2011). Large-scale $\mathrm{Co}_{3} \mathrm{O}_{4}$ nanoparticles growing on nickel sheets via a one-step strategy and their ultra-highly reversible redox reaction toward supercapacitors. J. Mater. Chem. 21, 18183-18185. doi: 10.1039/c1jm14173b

Yuan, L., Lu, X. H., Xiao, X., Zhai, T., Dai, J., Zhang, F., et al. (2012). Flexible solidstate supercapacitors based on carbon nanoparticles $/ \mathrm{MnO}_{2}$ nanorods hybrid structure. ACS Nano 6, 656-661. doi: 10.1021/nn2041279

Zhang, C., Yin, H., Han, M., Dai, Z., Pang, H., Zheng, Y., et al. (2014). Two-dimensional tin selenide nanostructures for flexible all-solid-state supercapacitors. ACS Nano 8, 3761-3770. doi: 10.1021/nn5004315

Zhang, D., Yan, H., Lu, Y., Qiu, K., Wang, C., Tang, C., et al. (2014). Hierarchical mesoporous nickel cobaltite nanoneedle/carbon cloth arrays as superior flexible electrodes for supercapacitors. Nanoscale Res. Lett. 9:139. doi: 10.1186/1556-276X-9-139

Zhang, G., and Lou, X. (2013). Controlled growth of $\mathrm{NiCo}_{2} \mathrm{O}_{4}$ nanorods and ultrathin nanosheets on carbon nanofibers for high-performance supercapacitors. Sci. Rep. 3:1470. doi: 10.1038/srep01470

Zhang, G., Wu, H., Hoster, H., Chan-Park, M., and Lou, X. (2012). Singlecrystalline $\mathrm{NiCo}_{2} \mathrm{O}_{4}$ nanoneedle arrays grown on conductive substrates as binder-free electrodes for high-performance supercapacitors. Energy Environ. Sci. 5, 9453-9456. doi: 10.1039/c2ee22572g

Zhang, S., and Pan, N. (2015). Supercapacitors performance evaluation. Adv. Energy Mater. 5:1401401. doi: 10.1002/aenm.201401401

Zhang, X., Shi, W., Zhu, J., Kharistal, D. J., Zhao, W., Lalia, B., et al. (2011). High-power and high-energy-density flexible pseudocapacitor electrodes made 
from porous $\mathrm{CuO}$ nanobelts and single-walled carbon nanotubes. ACS Nano 5 , 2013-2019. doi: 10.1021/nn1030719

Zhang, Y., Huang, Y., and Rogers, J. (2015). Mechanics of stretchable batteries and supercapacitors. Curr. Opin. Solid State Mater. Sci. 19, 190-199. doi: 10.1016/j.cossms.2015.01.002

Zhao, J., Lu, Z., Shao, M., Yan, D., Wei, M., Evans, D., et al. (2013). Flexible hierarchical nanocomposites based on $\mathrm{MnO}_{2}$ nanowires/CoAl hydrotalcite/carbon fibers for high-performance supercapacitors. RSC Adv. 3, 1045-1049. doi: 10.1039/C2RA22566B

Zhao, Y., Liu, J., Horn, M., Motta, N., Hu, M., and Li, Y. (2018). Recent advancements in metal organic framework based electrodes for supercapacitors. Sci. China Mater. 61, 159-184. doi: 10.1007/s40843-017-9153-x

Zhou, C., Zhang, Y., Li, Y., and Liu, J. (2013). Construction of high-capacitance 3D CoO@polypyrrole nanowire array electrode for aqueous asymmetric supercapacitor. Nano Lett. 13, 2078-2085. doi: 10.1021/nl400378j

Zhou, Z., Wu, X., and Fong, H. (2012). Electrospun carbon nanofibers surfacegrafted with vapor-grown carbon nanotubes as hierarchical electrodes for supercapacitors. Appl. Phys. Lett. 100:023115. doi: 10.1063/1.3676193
Zhou, Z., Wu, X., and Hou, H. (2014). Electrospun carbon nanofibers surface-grown with carbon nanotubes and polyaniline for use as high-performance electrode materials of supercapacitors. RSC Adv. 4, 23622-23629. doi: 10.1039/C4RA0 $0964 \mathrm{~A}$

\section{Conflict of Interest Statement: KR is employed by UbiQD, Inc.}

The remaining authors declare that the research was conducted in the absence of any commercial or financial relationships that could be construed as a potential conflict of interest.

Copyright (C) 2019 Palchoudhury, Ramasamy, Gupta and Gupta. This is an openaccess article distributed under the terms of the Creative Commons Attribution License (CC BY). The use, distribution or reproduction in other forums is permitted, provided the original author(s) and the copyright owner(s) are credited and that the original publication in this journal is cited, in accordance with accepted academic practice. No use, distribution or reproduction is permitted which does not comply with these terms. 